\title{
CHALLENGES OF ELECTRONIC INFORMATION RESOURCES IN ACADEMIC AND RESEARCH LIBRARIES: NEED FOR A POLICY
}

\author{
Tumsifu Elly ${ }^{1}$, Mariam Ally, Wanyenda Chilimo and Alfred Sife ${ }^{3}$
}

\begin{abstract}
This paper discusses the role of policy for proper and efficient library services in the electronic era. It points out some of the possible dangers of embarking in electronic resources without a proper focus at hand. Thus, it calls for today's librarians and policy makers to brainstorm and come up with working policies suitable to Africa's social, economic and ICT infrastructure framework. New approaches in acquisition, accessing, sclection, preservation and choices on whether to operate digital, or combine traditional print and digital resources in the library have to be worked out and adopted. Therefore, policies, which articulate libraries' vision and mission, are important for proper electronic information resources assimilation in the libraries.
\end{abstract}

\section{Introduction}

It is widely accepted that development in Information and Communication Technology (ICT) affect every sector and institution. Libraries are among institutions that have been affected by developments in ICT in their functions. It is true that the role of the library will in the electronic environment remain the same: to collect, organize, access and preserve information, but it is possible that themanner in which these functions are handled will change. There is therefore a need to address the effects of this technology and ensure proper harnessing of its potentials in libraries. Currently most libraries in developing countries like Tanzania have already embarked on electronic information resources without implementing policy to guide the entire process, an activity without a view?

For effective and efficient adoption and application of ICT by libraries there is a need to have policies to guide the entire process of information provision by the libraries. These should focus on present and/ or anticipated effects, of ICT in libraries. However there is a need to have sets of guidelines

${ }^{1}$ Tumsifu Elly - Assistant lecturer - Faculty of Commerce and Management, University of Dar es Salaam

${ }^{2}$ Mariam Ally - Economist - Planning and Policy Department of the Ministry of Health, Tanzania

${ }^{3}$ Wanyenda Chilimo and Alfred Sife - Assistant librarians, Sokoine University of Agriculture, Tanzania. 
explaining, the selection, acquisition, access, use and preservation of digital information in libraries alongside with the traditional print resources.

\section{Some challenges of electronic resources to libraries}

Developments in ICT have presented both challenges and opportunities to the libraries. ICT with its dual edge of promise and threat has changed the way libraries function. Everything in and around the library is changing: services, technologies, organizational constructs, ownership and access policies, values and a lot more (Marcum, 1997; Riggs, 1997). These changes affect all stakeholders in the libraries from librarians, users, authors, to publishers. Rowlands and Bawden(1999) stress that ICT as a technology has brought about misunderstanding by both policy and decision makers on the aims and objectives of the libraries. However, the challenges do not only emanate from the novelty of the technology but also from the effects it has to the entire library culture. Some stakeholders are actively changing their roles for example, most publishers are now involved in archiving electronic information thus, assuming the responsibility of a long-term availability. Libraries at this time are but operating in a rather fleeting environment, which needs guidelines for its mission, visions and obligations in a more efficient line of thinking.

\section{Selection}

Although many selection criteria for electronic resources are the same as those for print, it is evident that electronic resources present special problems that call for new selection policy. What selection criteria can be used for electronic resources? This is a very important question for librarians. Ungern-Stemberg (2000) provides some issues to be considered when developing criteria for the selection of electronic resources. These issues are related to user needs, essential technology, staff expertise; tools for storage, implementation and access; vendor reliability and cost.

\section{Acquisitions}

Although acquisitions procedures may vary depending on the library's mission and resources, all libraries have some goals in common. These include acquiring materials as quickly and economically as possible. Effective working relationships with vendors are very important as well. Depending on the level of the technology a library system should ensure that patrons needs are met. Thus strategic acquisition criteria should be set which will of course guide the acquisition of both print and electronic resources

Libraries are confronted with decisions to make on whether they should go for print subscription only, electronic subscription only, or hybrid collection i.e. both electronic and print subscriptions. Though the latter approach is already a common place in most of the libraries in Africa, we are 
according to Darch (2001) unable to predict with any confidence how the selection of digital or print resources is going to function in the immediate future. Furthermore, hard and intelligent decisions have to be made on the type of information resources that are or will only be available in one format either electronic or printed forms without their equivalent substitute formats.

\section{Preservation of the digital information}

The electronic resources have a lot of other challenges to libraries as highlighted by Schwartz (2000) including; the associated difficulties in preserving and archiving, the worries about media deterioration over time and technological obsolescence as software and hardware platforms change. In this case relying on standards to be persistent is risky as attempting to preserve hardware and software.

In order to provide continuous electronic information services, libraries should not have only current information sources but also past sources. Preserving these collections is a big challenge. For example, according to IFLA and IPA (2002), it is estimated that much of the digital material with no print equivalent has already been lost, as some producers have deleted them without recognizing the importance of the long-term preservation. Therefore, preservation of the digital information is becoming an increasingly important challenge for libraries although policies and techniques for preserving this format of material remain unsettled.

There have been tremendous changes in hardware from mere simple computers to more complicated super computers. Software necessary for information preservation, retrieval and sharing has not only been changing but also presents difficulties arising from non standardization (incompatibility) of both hardware and software. However, each time these changes occur one needs to update the entire system to cope with the trend otherwise everything goes wrong. Migrating files as platform change is one of the possible approach but which requires diligent planning and good record keeping. For developing countries based on their social economic situation, this implies not only technological but also fiscal and human resource dearth. Therefore, there is a need for efforts on standards and research for digital archiving and preservation.

The unknown future electronic world needs to be tackled with care. Library services via computers both online and on CD ROM is currently uncertain and awkward for most of the Africans libraries. Therefore, ensuring access to the electronic information resources, stability of publishers' services and communications are among worries of today's librarians. Payment for the access of the online information for example, calls for changes in the dynamics of acquisition. Most of the electronic resources are now rented to and not owned by libraries. Problems arising from slow Internet connectivity, low bandwidth and a lot of other online 
problems render most of the information services inefficient. Moreover, access to the online information if subscription is later discontinued or a publisher runs bankrupt or goes out of the business, archiving and access to the archived information becomes uncertain indefinitely in the future aggravates further the situation. Therefore, selection, access, subscription start and end dates, are huddles which needs critical attention.

\section{Planning and budgeting}

Another challenging aspect of ICT is cost in terms of required infrastructure, trained human resources, awareness and skills among users. This implies that libraries and their parent institutions should come up with policies, not only to guide its activities but also to ensure that the little financial resources out of the shrinking budgets are effectively and efficiently allocated through proper planning. Taylor quoted by Hardy, et al (2002) pointed out that no system will function where there is no mutual benefits, shortage of funds, and lack of mutually agreeable and strict rules. This means that library activities need to be well organized to have little or no conflicts in pursuits between and within the organization.

\section{Sustainability}

There is also a challenge related to sustainability at which libraries in developing countries can operate in such ephemeral technological world. This is mainly due to the fact that ICT is one of areas that are rapidly changing. Therefore most developing countries cannot cope with these rapid changes in terms of acquiring, retrieving, processing and preserving information. Butcher (1999) alerts that the technology is not only outpacing budgets but is very close to outpacing our ability to manage it. The budgetary implications have to be outlined taking into consideration donor dependency syndrome of most libraries in developing countries. Katundu (1998) revealed that most budgets the Tanzanian libraries are donor dependent; thus, donors enable them to operate efficiently. This affects ICT planning, and development in the said libraries. It is therefore important for the libraries to establish their own policies, which will address its functions to ensure that information needs of its patrons are met in a sustainable manner. In other words embarking into electronic resources without policies and guidelines may be as good as defining library functions demise. We need not learn from mistakes but rather anticipate the future in order to minimize possible errors.

\section{Copyright}

Copyright issues are one of the serious problems facing libraries mostly in developing countries in providing electronic information and services. The problem for many libraries is that, unlike private businesses or publishers that own their information, libraries are, for the most part, simply caretakers 
of information. They do not own the copyright of the material they hold. It is unlikely that libraries will ever be able to freely digitize and provide access to the copyrighted materials in their collections. This is a great challenge, which needs to be changed by library community to provide effective information services.

\section{The need for policy}

While few research and academic institutions in Tanzania have ICT policies in place, these policies do not necessarily address library needs. There are a lot of activities which are housed in the libraries that cannot be hosted anywhere in an institutional ICT policy. For example the ICT Policy and Guidelines for Sokoine University of Agriculture touches briefly (less than a page) about the university library (SUA, 2002). Therefore it is important to have ICT policies specifically for libraries.

The challenges of electronic resources to the libraries and their entire services necessitate further the need for policies and guidelines. In other words ICT guidelines and policies of today will determine by and large the future outlook of the information services rendered by the libraries. Atkinson (1996) noted that, if institutions, led by libraries do not use the advances in information technology to achieve their goals, then the same technology may restrict access to information. Therefore, it is pertinent to consider systems and mechanisms for fulfilling present and future information needs of the patrons.

The service capacity of libraries will be shaped by the technologies, standards and models adopted today (Rowlands and Bawden, 1999). Meeting the strategic information needs of academicians will by and large be determined by library ICT policies. The importance of policy and planning is reflected in the success or failure of any program endeavor.

According to Rizzo (1980) policy is a written statement that reflects the values and beliefs of an organization or unwritten but widely held opinions about matters central to an organization. It contains statements of action and inaction on matters relevant to, and which complies with the organizational goal. Policies are supposed to be living documents (dynamic), adaptable to change and growth, providing guidelines that can be modified. Therefore, one of the possible mechanisms to ensure smooth application/ use of electronic resources in the libraries is to have ICT policy in place.

The ICT policy provides guidelines for:

- Monitoring and evaluating library ICT activities and outcomes from time to time

- ICT development and application in the library

- Assessing areas of weakness and strengths for ICT application in the library 
- Making decisions on issues like selection, acquisition, preservation and archiving, of information architecture.

- Acquiring hardware and software to minimize incompatibility and obsolescence as software and hardware change.

- Developing infrastructure to accommodate electronic resources and related library ICT capacity building

- Ensuring that both electronic and traditional information resources are managed efficiently.

- Ensuring a smooth transition to electronic resources from print resources format.

The axiom that libraries in Africa and particularly in Tanzania are characterized by lack of funds, trained ICT staff and poor ICT infrastructure, compels libraries to have its activities organized and monitored clearly by putting in place procedures and policies for electronic resources. Librarians need to brainstorm creatively on guidelines and procedures for proper ICT integration in the libraries.

\section{Discussion and way forward}

Electronic information presents libraries with planning and policy issues that need more attention than traditional print format. Access, acquisition, preservation and archiving, the costs associated with staff and users training, and associated changes in format and hardware/software requirements need a different approach. A challenge today is for academic and research librarians jointly or individually to establish working ICT policies. This paper suggests joint efforts with a multi pronged approach in establishing these policies, thereafter some modifications that suits individual libraries may be done from the parent policy guidelines. Both redundancy and interaction between institutions will increase the robustness of the integrity of electronic information. Critical decisions have to be made to rescue libraries from the current state of dreams into real activities with a vision. Therefore a call is being made for a policy from which planning becomes effective and realistic. The situation in the developed countries is different from developing countries because most publishers and suppliers of ICT resources are from developed countries. African librarians consequently need to have strong consortia guided by policies and guidelines to influence standardization and continuous accessibility of both formal and informal electronic resources to at least meet their needs. We need to have ability to influence pricing mechanisms and subscription conditions by establishing consortia in the region but with clearly known policies guiding our missions and visions.

Currently, most libraries put effort in acquiring and establishing digital information resources. Establishing electronic resource (ICT) guidelines for 
libraries is not seen as a priority. Major questions that relate to the failure of ICT in the libraries in Africa include:

- Can they (libraries in Africa) sustain the ephemeral nature of the electronic resources?

- Can they be sustained with or without donors in future?

- What are the possible and reliable approaches to electronic resource by our libraries?

All of these questions and others have to take into consideration the fact that information is far from the minds of most managers and decision makers in developing countries. Establishing policies may be the stone that most of the libraries has to step on at this time rather than spending a lot of resources, including time and money, in acquiring and using electronic resources without established ICT policies.

\section{Possible steps in establishing a policy in brief:}

There is a need to:

- Define a policy and what it tries to achieve

- Collect data which includes what make up library ICT/ electronic resources

- Developing options with advantages and disadvantages of each and thereafter choosing the most cost effective option

- Communicating how does the policy reflects library electronic resource needs

- Monitoring of $\mathrm{ICT}$ activities

- Evaluating, and answering question like, what has the library ICT achieved?

\section{Conclusion}

The electronic information resources have significant influence on libraries; consequently they are an issue of concern to librarians. Librarians in Africa are more affected by technology compared to libraries in the developed countries because of factors like budgets, human resource and physical resources that are lacking. Libraries in Africa and Tanzania in particular must have their activities well articulated and organized. They must have ICT policies in place as a way forward. Librarians need to brainstorm on possible approaches in integrating ICT in the libraries rather than without any view. 


\section{References}

Atkinson, R (1996). 'Laying claim to the control zone: library functions scholarly communication and foundation of digital library; Library quarterly $66 ; 248$

Butcher, K (1999). 'Reflections on academic libtarianship'; Journal of academic librarianship 25 (5) 350-353

Jacqueline, J Clamroch, J., Byrid and S. Sowell (2001). 'Strategic planning: politics, leadership and learning'; Journal of Academic librarianship $27(5) 372-378$

Darch, C (2001). The 'Alexandrian' library, digital resources, and the shrinking public domain: a critique of the current model for delivering academic information in Africa; University of Dar es salaam Library Journal 3(1\&2) 25-39

Hardy, R. O. Charles and Robbert I (2002). 'Pricing strategies and models for the provision of digitized texts in higher education'; Journal of information science 28(2) 97-110

IFLA and IPA (2002). 'Preserving the Memory of the World in Perpetuity: a joint statement on the archiving and preserving of digital information', http://www.ifla org/V/press/ifla-ipa02.html (read on 8/10/2002)

Katundu, D.R.M., (1998). 'The use and sustainability of information technology (IT) in Academic and research libraries in Tanzania'; (Ph.D) Depatment of information studies, University of Natal.

Marcum D.B (1997). 'Editorial: The digital librarian'; Journal of academic librarianship 23(2) 79-80

Mead, L. M; (1993). 'The interaction problem in policy analysis'; Policy science, $16(1): 45-66$.

Riggis, D.E., (1997). 'What is in Store for Academic Libraries? Leadership and Management issues'; Journal of Academic Librarianship 23 (1) 38

Rizzo, J.R (1980). Management for librarians; fundamentals and issues. Greenwood Press: Connecticut

Rowlands, I and D, Bawden (1999). 'Digital libraries : assumptions and concepts'; Libri- International journal of libraries and information services 49(4) 181-189

Sokoine University of Agriculture (2002). 'Information and Communication Technology Policy and Guidelines'.

Schwartz, D (2000). 'Digital libraries: an overview': Journal of academic librarianship 26(6)

Unesco (1990). National information policies: a handout on the formulation, approval, implementation and operation. Paris:UNESCO

Ungern-Sternberg, S (2000). 'Content management in an electronic environment'. Paper presented at the workshop for librarians: Libraries for a global future. Kent, United Kingdom, 6-8 April 2000. 